\title{
Revolucionarios con clase. Vida, cultura y fortuna de la familia Sainz de Baranda, 1750-1850
}

\author{
Jesús CRuz *
}

A su regreso de un viaje por Francia y Bélgica que el perspicaz Mesonero Romanos realizó en 1841, aseguraba traer en su cabeza mucho ruido de proyectos económicos y literarios. Aquel paseo por las industriosas calles de París y sus contactos con otras formas de vida habían impresionado profundamente a nuestro castizo escritor. Decía haberse formado un plan de vida diametralmente opuesto al que seguía antes de su viaje. Creía haber aprendido en él lo que vale una buena utilización del tiempo para sacar más provecho del trabajo; «pero (afirmaba Don Ramón), iqué se yo por qué!, así que me ví en Madrid, empecé a levantarme a las siete, luego a las ocho, después a las nueve; empecé a salir a las doce; a sentarme en las librerías a la una, y en las tiendas de la calle de la Montera a las dos; a comer la inevitable olla a las tres; a echar la siesta a las cuatro, y levantarme a las seis; a ir al Prado a las siete, y al café o al teatro a las ocho; a la tertulia a las once; a cenar a las doce, y a acostarrne a la una; y así, un día tras otro, se me ha ido el tiempo sin realizar mis proyectos" ${ }^{1}$.

Quien esto escribiera no fue precisamente el prototipo de señorito holgazán o de hidalgo pretencioso tan común a la época y a su literatura. Por el contrario fue un escritor prolífico y sagáz, amén de un hombre que trabajó obsesivamente a lo largo de su vida por modernizar la sociedad

* Universidad de California, San Diego.

${ }^{1}$ Mesoneros Romanos, Ramón de, Recuerdos de viaje por Francia y Bélgica, Madrid, 1983, pág. 289. 
española. Pero Mesonero, como otros muchos hombres de su época, era consciente de que ninguna transformación sería posible si ésta no se operaba más allá de las instituciones públicas emanadas de la cotidiana actividad política. Lo que había que cambiar eran ciertos hábitos de la sociedad española. Algo que él denominaba "cultura social» y que en nuestros días es uno de los centros de interés de los científicos sociales.

En efecto toda relación social, ya sea de dominación o de cualquier otro carácter, tiene siempre un contenido cultural. Para Gramsci dicho contenido se manifiesta a través del lenguaje como instrumento utilizado por las clases dominantes para imponer una «hegemonía cultural» ${ }^{2}$. De forma que en toda sociedad hay una cultura dominante que marca, en definitiva, las pautas de comportamiento social y que se manifiesta con cierta independencia respecto del sistema productivo. La forma en la que se producen las alternancias de esas culturas hegemónicas es algo más complejo, pero Gramsci nos enseña dos cosas: en primer lugar el valor que tiene el análisis cultural para comprender el proceso social. En segundo lugar que no hay que entender la cultura como una superestructura más o menos determinada por la infraestructura productiva.

Entonces en el proceso de formación de cualquier sistema de normas, significados, valores y símbolos, o sea de una cultura, entran en juego factores no procedentes exclusivamente de la estructura productiva ${ }^{3}$. Durkheim, antes que Gramsci, en sus estudios sobre las religiones primitivas, demostró la importancia que tienen los sistemas simbólicos para entender los cambios o las persistencias en un determinado contexto social ${ }^{4}$. Su gran aportación consistió en combinar dos categorías analíticas que en las tradiciones cartesiana y kantiana encajaban bastante mal, me refiero al conocimiento y a la acción. Para Durkheim, la vida social debe explicarse no sólo por la concepción de los que en ella participan, sino por las causas profundas que escapan a la conciencia. Claro, que a pesar del valor que el conocimiento y las estructuras lógicas tienen en su teoría, Durkheim al igual que Marx, colocaba en el plano de las estructuras objetivas la razón definitiva para explicar el cambio social.

${ }^{2}$ Gramscl, Antonio, Scritti Politici, Roma, 1979, págs. 17 y 110.

${ }^{3}$ Para una definición de cultura ver WILLIAMS, Raimond, Culture, Glasgow, 1981, págs. 10 y ss.

${ }^{4}$ THOMPson, Kenneth (edits.), Readings from Emile Durkheim, Nueva york, 1985, págs. 14-20. 
En la tradición estructuralista Lévi-Straussiana los sistemas simbólicos aparecen como algo enraizado en la conciencia de los hombres ${ }^{5}$. Sin embargo, la manera en que esas estructuras afectan al cambio social es algo que Lévi-Strauss dejó sin resolver, y que viene siendo el objeto de la sociología y la antropología del post-estructuralismo. En mi opinión, quien mejor está atajando este problema es el sociologo francés Pierre Bordieu a través de su visión constructivista del proceso social y su utilización del concepto de «habitus». Por constructivismo Bordieu entiende la existencia de una génesis social en la cual actúan lo que el denomina campos o grupos y que normalmente se conocen como clases sociales. Por «habitus» entiende una serie de estructuras internas de percepción, de pensamiento y de acción que tienen una relativa autonomía y cambian con más lentitud que las estructuras económicas ${ }^{6}$. Estas estructuras internas de percepción, pensamiento y acción están profundamente arraigadas a la conciencia de los hombres a través de la costumbre y la norma. Incluso donde los historiadores percibimos cambios revolucionarios este habitus permanece poco alterado. Es como si con las piedras de un castillo medieval construyéramos un funcional rascacielos. Podríamos tal vez conseguir un edificio innovador en su aspecto exterior pero mucho menos en su estructura.

Esta dicotomía entre cambios objetivos y persistencia de valores subjetivos es lo que, en definitiva, estaba denunciando Don Ramón de Mesonero, aún a riesgo de anticiparse con su intuición a la moderna sociología y a la antropología cultural. Su cultura social no se refería ni más ni menos que a la interacción entre los agentes sociales y ese conjunto de normas, significados, valores y símbolos que los antropólogos denominan cultura. En resumen a la interacción entre clase o grupo social y cultura, algo que viene siendo el centro de atención de la historia social en los últimos años ${ }^{7}$.

En efecto, en las dos últimas décadas ha tenido lugar un importante debate entre historiadores sociales sobre la naturaleza de los cambios que se operaron en las sociedades europeas entre 1750 y 1850 . El modelo de interpretación tradicionalmente asumido tiene su fundamento en la aparición de una nueva clase social denominada burguesía. Dicha clase social fue haciéndose progresivamente con el poder y fue transfor-

\footnotetext{
5 Jenkins, Alan, The Social Theory of Claude Levi-Strauss, Nueva York, 1979, págs. 96 y ss.

${ }^{6}$ Bordieu, Pierre, Cosas dichas, Madrid, 1988, págs. 127 y 128.

7 En una tradición revisionista que arranca del conocido libro de ToMPSON, Edward P., The Making of English Working Class, Nueva York, 1963.
} 
mando las estructuras jurídicas y sociales en función de sus propios intereses, que no eran otros que aquellos que favorecieran el desarrollo del capitalismo. A través de las instituciones liberales consiguieron un control del estado, liberaron al individuo y posibilitaron una ordenada administración de gobierno. Finalmente la expansión del principio de laissez faire proveyó a los individuos de un nuevo espíritu capaz de hacerlos más competitivos en las nuevas condiciones del mercado. Todo ello fue posible gracias al impulso revolucionario de esa nueva clase social, de manera que el proceso de acceso al poder se realizó a través de una revolución burguesa o revolución liberal burguesa.

Este modelo parte de la utilización de una serie de presupuestos teóricos procedentes de la concepción marxista de la historia aunque, como ha demostrado Theda Skocpol, no son tan grandes las distancias entre lo que dicen algunos teóricos de la modernización y los que explican el cambio por el protagonismo de una burguesía revolucionaria ${ }^{8}$. Dichos presupuestos fueron creados tomando como punto de referencia la evolución histórica de países donde se habían producido cambios económicos y sociales importantes ya en la segunda mitad del siglo xvIII. De manera que el modelo partía de la observación parcial de un espacio social y económico geográficamente limitado a algunos países del Norte de Europa. Además para su construcción se habian tenido mucho más en cuenta los cambios producidos en las estructuras económicas y políticas que en la sociedad misma.

La influencia estalinista posterior a los años 40 condujo estos modelos de interpretación a posiciones reduccionistas de corte economicista. Los modos de producción se convirtieron en procesos cerrados y rígidos de sucesión histórica donde todo ocurría conforme a reglas preestablecidas ${ }^{9}$. Fue a partir de los años 60 cuando la influencia de Gramsci, el estructuralismo y los teóricos de la modernización empezó a abrir las vías para una revisión del modelo. La consigna era apartarse de la tentación reduccionista para ponerse a estudiar el problema de la formación de las clases supuestamente protagonistas del cambio. A esto ayudó especialmente una actitud más pragmática que condujo a una nueva definición del concepto de clase social menos dependiente de lo económico, y más preocupada por lo ideológico. En su Formación de la clase obrera inglesa, E. P. Thomsom mostraba como una clase no lo es

${ }^{8}$ Sckocpol, Theda, States and Social Revolution: A Comparative Analysis of France, Russia and China, Cambridge, 1979, págs. 3-43.

${ }^{9}$ Cardoso, Ciro F. S. y Pérez Brignoli, Héctor, Los métodos de la Historia, cap. I, Barcelona, 1976. 
sólo por lo que es objetivamente, sino también por su propia voluntad por serlo. Por eso una clase no se define como un agregado de agentes con una misma posición en el proceso productivo, sino como un conjunto de normas, hábitos, significados, costumbres y símbolos con los que se identifican grupos de individuos ${ }^{10}$.

En los años 70 y 80 el revisionismo del modelo clásico de revolución burguesa se ha acelerado a escalas nacionales. Los historiadores franceses se han sentido más atraídos por saber quiénes fueron realmente los auténticos dirigentes del proceso revolucionario abierto en 1789. Su conclusión es que por aquellos años no existía en Francia una auténtica burguesía y que tampoco existía un claro divorcio entre ideas liberales y nobleza ${ }^{11}$. En Alemania parece que nunca existió una clara hegemonía cultural burguesa a lo largo del siglo XIX, por el contrario prevaleció un sistema de valores no sólo sociales sino también políticos cuyo origen era claramente nobiliario ${ }^{12}$. En el único lugar donde existió una auténtica burguesía fue en Inglaterra, pero también fue el país europeo con menos conflictividad social de todo el siglo XIX. Precisamente allí el debate entre historiadores se dirige a encontrar una explicación para esa ausencia de revolución ${ }^{13}$.

${ }^{10}$ Para una puesta ai día sobre este debate ver Reddy, William M., Money and Liberty in Europe. A Critique of Historical Understanding, Cambridge, 1987, págs. 1-23.

$"$ Sobre el problema de la definición de los grupos sociales que protagonizaron el proceso ver FURET, François, "Le catéchisme révolutionaire", Annales: Economies, sociétés, civilisations, 26, [1971], págs. 255-89. Una revisión general sobre este debate puede encontrarse en DOYLE, William, Origins of the French Revolution, Oxford, 1980. Sobre las actitudes políticas de ciertos grupos dirigentes ver Chaussinand-NogARET, Guy, La noblesse au xvilie siècle: de la féodalité aux Lumières, París, 1976, págs. 39-64.

${ }^{12}$ La revisión se inició en torno al análisis histórico del fracaso revolucionario de 1848. Ver Krieger, Leonard, The German Idea of Freedom: History of a Political Tradition, Chicago, 1957. Sobre la ausencia de una auténtica burguesía o de valores burgueses en la sociedad alemana del siglo XIX ver BLEIBER, Helmut, en Bourgeoisie un bürguerliche Umwälzung in Deutschland, 1789-1871, Berlín, 1977, págs. 193-95. También MAYER, Arno, La persistencia del Antiguo Régimen. Europa hasta la Gran Guerra, Madrid, 1984, págs. 79127. DiefEndorf, Jerry M., Businessmen and Politics in the Rhineland. 1789-1934, Chicago, 1984; HaRRIS, José y THANE, Pat, «British and European Bankers, 1880-1914: An Aristocratic Bourgeoisie", en Thane, Pat, (edit.), The Power of the Past: Essays for Eric Hobsbawn, Cambridge, 1984, págs. 215-34.

${ }^{13}$ Sobre le cáracter de la revolución inglesa ver Russel, Conrad, Parliament and English Politics, Oxford, 1979; STONE, Lawrence, The Causes of the English Revolution. 15291642. Nueva York, 1972. Uno de los problemas centrales en el debate sobre la ausencia de revolución en el siglo xix se refiere a los niveles de vida de las clases trabajadoras, una puesta al día sobre esta discusión puede encontrarse en TAYLOR, Arthur J., (edit.), The Standard of living in Britain in the Industrial Revolution, Londres, 1975; ver también DEANE, Phyllis, La primera Revolución Industrial, Barcelona, 1986, págs. 255-71. 
En lo que se refiere a España sólo parece haber unanimidad en una cosa que es en mantener el paradigma a pesar de lo multivalente de su contenido. A estas alturas más que de una revolución burguesa resultaría más correcto hablar de una serie de variantes de la revolución burguesa. Para algunos dicha revolución se culminó en su vertiente antifeudal pero no en su vertiende democrática ${ }^{14}$. Revolución burguesa sí, dirán otros, pero con un miedo desorbitado a la revolución popular, primero inspirada por la Revolución Francesa, después por el socialismo ${ }^{15}$. Por fin hay quienes sostienen ante todo una revolución política cuyo carácter fue esencialmente liberal, claro que ésta fue inspirada por la burguesia ${ }^{16}$. En definitiva todos coinciden en la existencia de una clase burguesa con suficiente capacidad como para dirigir un proceso de transformación revolucionaria, aunque éste estuviera repleto de desequilibrios. Pero todavía a estas alturas tenemos una idea bastante vaga sobre quienes fueron esos burgueses y cual fue su cultura social, ni siquiera sabemos si dicha cultura fue hegemónica en la España del siglo XIX.

Como mucha gente, no importa del lugar que sean o del tiempo en que vivan, los Sainz de Baranda pensaron con frecuencia en su futuro. Se preocuparon por el presente, el pasado y el porvenir de su prole. Participaron de la vida pública, no sólo de aquella que de forma más o menos abstracta conocemos como estrategias económicas o procesos políticos, sino también de las manifestaciones de sociabilidad cotidiana como las fiestas, las celebraciones, los ritos y la vida de sociedad. Pen-

${ }^{14}$ Ver Pérez Garzón, Juan Sisinio, Milicia nacional y revolución burguesa. El prototipo madrileño. 1808-1874, Madrid, 1978, págs. xxiii-xxii. Del mismo autor, «La revolución burguesa en España: Los inicios de un debate científico. 1966-1979", en TUÑÓN DE LARA, Manuel (y otros), Historiografía española contemporánea. $X$ Coloquio del Centro de Investigaciones Hispánicas de la Universidad de Pau. Balance y resumen, Madrid, 1980, págs. 91-145. Una más reciente aportación en esta misma línea de interpretación es la de Sebastià, E. y Piqueras, J. A., Perviviencias feudales y revolución democrática, Valencia, 1987, págs. 13-19.

${ }_{15}$ Gll Novales, Alberto, (edit.) «Las contradicciones de la revolución burguesa española", La revolución burguesa en España, Madrid, 1985, págs. 45-58. Del mismo autor, El Trienio liberal, Madrid, 1980 , págs. 60-70.

${ }^{16}$ ARTOLA, Miguel, Antiguo Régimen y revolución liberal, Barcelona, 1978. 
saron, finalmente, en su privacidad, en cómo mejorar sus condiciones de vida en función de sus necesidades y de sus deseos, y en cómo conducirse para mantener su respetabilidad. Las actitudes o los posicionamientos que los Sainz de Baranda adoptaron en cada momento de su historia familiar, respondieron a una combinación entre lo tradicional y lo innovador. El hábito y la costumbre pesaron tanto o más que la política o la economía a la hora de tomar decisiones que pudieran transcender socialmente. El análisis de dichas actitudes y posicionamientos va a ser el objetivo central de este trabajo. Dicho de otra manera, de lo que se trata es de intentar definir el "habitus» de una familia muy representativa de la denominada burguesía española, precisamente en tiempos de la revolución burguesa. El ejemplo pudiera tener un valor paradigmático. Podría utilizarse para definir en parte las características de la cultura social de un grupo muy representativo de la élite española en la transición del siglo XVIII al XIX. Lo que interesa es saber hasta que punto estos «burgueses" se comportaron realmente como tales y hasta que punto fueron capaces de crear una cultura hegemónica. Lo que debemos preguntarnos es si realmente existió una cultura burguesa en el Madrid del siglo XIX o sólo retazos de algo que vagamente podría considerarse como tal.

A muchos madrileños les es muy familiar el apellido Sainz de Baranda. La mayoría lo identifican con una calle y con un alcalde que, no se sabe a ciencia cierta cuando, lo fue de la villa de Madrid. Otros esbozan una sonrisa maliciosa cuando se les pregunta, porque asocian el apellido con una coplilla obscena, que no hace muchos años formaba parte de cierta cultura underground, característica de los estudiantes en colegios católicos de pago ${ }^{17}$. La utilización del apellido para la cancioncilla es puramenta casual, al que la compuso le debió de sonar bien y nada más. Sin embargo, lo de la alcaldía sí es historia y por aquí podríamos empezar.

Fue en octubre de 1812, cuando los franceses amenazaban de nuevo con volver a Madrid recuperados de la derrota infligida por el ejército aliado, cuando un personaje llamado Don Pedro Sainz de Baranda y Gorriti se hizo cargo de la alcaldía y de la jefatura política de Madrid. Hasta esa fecha, dice Mesonero Romanos, apenas si se le conocía, pero demostró ser portador de un alma superior y estar dotado de un ardiente patriotismo y valor cívico amén de un alto sentido de la autoridad, res-

17 Existe actualmente en la calle Sainz de Baranda un bar llamado «The Chunta» que confirma mi información al respecto. 
ponsabilidad y orden ${ }^{18}$. Pero quizá el mayor mérito de Sainz de Baranda es el que le atribuyó Moratin de haberse hecho cargo de la regencia constitucional de Madrid, cuando las gacetas aseguraban que los magistrados constitucionales perecían arcabuceados por los franceses ${ }^{19}$. Demostró así nuestro hombre ser un sincero y comprometido defensor del orden constitucional de 1812, y desde luego, un amante del orden y de la autoridad a toda costa. Defensor de la constitución en 1812 y 1820 , desembarcó en una suerte de fatalismo político, allá por los años 30 , durante su exilio, que le llevó al moderantismo en las décadas previas a su desaparición. Esta sería más o menos la fotografía pública del protagonista de una saga que empezó, sin embargo, en un espacio social algo más distante en el tiempo pero, como veremos, mucho menos distante en lo que a las expectativas vitales de sus miembros se refiere.

El primer Sainz de Baranda llegó a Madrid hacia 1750. Se trataba de Don Pedro Sainz de Baranda y Gándara, el menor de una familia de tres hermanos naturales de Quintanaedo. Era esta una pequeña aldea hoy desaparecida que se localizaba en la Merindad de Montija, al norte de la actual provincia de Burgos. En esta región los montes Cantábricos han formado una serie de valles que, a pesar de su aislamiento, han tenido que vivir siempre abiertos hacia el exterior para asegurar su subsistencia. Su estructura socio-económica se caracterizaba por el predominio de pequeñas unidades familiares agrupadas en torno a la casa o solar. Las economías familiares estaban orientadas hacia una agricultura con maíz y trigo como principales productos, que se complementaban con pequeñas explotaciones ganaderas. Eran estas tierras deficitarias en vino y trigo, alimentos fundamentales para la subsistencia de su población, por lo que sus habitantes se vieron siempre obligados a abastecerse de estos productos en regiones próximas. Sin embargo, eran excedentarios en productos procedentes de la explotación ganadera y en hierro que utilizaban para realizar transacciones comerciales con el exterior. De esta forma durante muchos años, se podría decir que desde la introducción del maiz en la península, los habitantes de estos valles tuvieron dos principales puntos de destino en sus rutas comerciales: por el norte, los puertos cantábricos, muy especialmente Bilbao; por el sur, las tierras de Castilla, donde destacaba Madrid como principal mercado castellano ${ }^{20}$. Por esta razón los valles de las Merindades y Encartaciones

18 De Mesonero Romanos, Ramón, Memorias de un setenton, Madrid, 1880, pág. 100.

19 Sainz de Baranda Aldama, Pedro, Recopilación de los méritos de D. Pedro Sainz de Baranda y Gorriti. Alcalde de Madrid en 1812 y 1820, Guadalajara, 1911, págs. 11-12.

${ }^{20}$ Sobre el papel de los puertos cantábricos, ver Basurto laRRañaga, Román, Comer- 
vivieron abiertos hacia el exterior a pesar de su abrupta geografía. A esta explicación económica habría además que añadirle la existencia de un sistema legal de transmisión de la propiedad, para entender el constante flujo de población excedentaria hacia el exterior. Dicha población compuesta mayoritariamente por los varones menores de cada grupo familiar, se dirigía hacia los lugares donde tradicionalmente se venían practicando los intercambios: los puertos cantábricos y la corte. Pero hay algo en las descripciones que algunos contemporáneos hicieron de la sociedad de aquellos valles que llama poderosamente la atención. Escribía en 1799 un ánimo articulista en el diario de Madrid refiriéndose al valle de $\mathrm{Ca}$ rranza, que los hombres y mujeres de aquella tierra adquirían desde la más tierna edad unos principios de educación nada comunes. Esto era debido a que en todos los pueblos principales había escuela de primeras letras con maestros escogidos por oposición. De manera que "apenas se encontrará en este país un hombre ni mujer que no sepa a lo menos leer, y los más saben escribir, cuidando del mismo modo con el mayor tesón y vigilancia de que sus hijos e hijas aprendan, y el despejo de aquellos naturales para todo, los inclinará a salir de su pais a buscar en otros lo que en él jamas encontrarán y pasando a la Corte y demás provincias del reino y de ambas Américas en que se dedican al comercio $y$ a las ciencias han hecho $y$ hacen grandes fortunas, de las cuales disfruta su propio país gran parte (...). Los naturales son poco inclinados a las armas y mucho menos a las artes, pues los pocos artesanos que hay en Carranza todos son forasteros. Viven las gentes honradamente y cuidan de criar sus hijos con cierta educación varonil digna de los siglos heroicos. El lujo es desconocido en el país y el traje, así de hombres como mujeres, es sencillo y su mayor esmero está en la limpieza" ${ }^{21}$.

La descripción nos sugiere una sociedad austera aunque no pobre, en la que predominaban individuos con un aceptable nivel de educación y una escasa inclinación hacia el trabajo manual. Un sistema de valores que sin ser el de la vieja nobleza rio deja de ser nobiliario, incluso con una pureza digna de "los tiempo heroicos.» Se trataba, sin duda, del sistema de valores de cierta hidalguía provincial que fue, en definitiva, la que formó la parte más numerosa de la élite de negocios de Madrid, así como una parte importante de la élite administrativa. $Y$ no es que, porque

cio y burguesía mercantil de Bilbao en la segunda mitad del siglo xvil. Bilbao, 1983. Respecto del papel de Madrid en la formación del mercado de la España interior, ver RinGRose, David R., Madrid y la economía española, 1560-1850. Ciudad, Corte y País en el Antiguo Régimen, Madrid, 1985.

${ }_{21}$ Diario de Madrid, 4 y 5 de diciembre, 1799, págs. 1469-71 y 1473-75. 
en aquellos paísajes existiera el privilegio de hidalguia universal, todos los vecinos disfrutan de un mismo estatus social. No hay duda de que había familias ricas y familias pobres y que aquéllas disponían de más oportunidades que éstas. Sin embargo, todo parece indicar que los que hacían fortuna, al menos en Madrid, pertenecian a linajes, si no económicamente prósperos, si al menos socialmente prestigiados.

Nuestros Sainz de Baranda (una rama de la familia) tenían su casa solariega en Quintanaedo donde lucian su escudo de armas. Habían tenido ocasión de probar su nobleza ya en el siglo XVII ante la Chancillería de Valladolid y en alguna orden militar. En su aldea eran respetados, aunque sabemos que no eran ricos, que no disponían de mayorazgo y que sus propiedades se limitaban a la casa y un reducido número de tierras. Sin embargo, en 1774 Felipe Sainz de Baranda, padre de Pedro, probaba de nuevo su hidalguía en Valladolid. El propio Pedro aparece empadronado como hijodalgo en Madrid hacia $1780^{22}$. Esto no quiere decir que Pedro no trabajara duro para abrirse camino en la corte, ni que, en cierto sentido, su ascenso social hasta convertirse en «burgués» respetable demuestre que la sociedad madrileña de finales del siglo XVIII no era tan estática. Pero me pregunto si para Pedro hubiera sido posible ese ascenso social si en vez de proceder de la Merindad de Montija hubiera sido gallego o asturiano.

Lo cierto es que en Madrid la suerte de los inmigrantes no dependía tanto de su capacidad de trabajo, como de sus posibilidades para encontrar los contactos necesarios que abrieran las vías del ascenso social. No era aquella una sociedad en donde se practicara la igualdad de oportunidades sino más bien todo lo contrario. Se podría hablar de un espacio social en el que la movilidad social respondía a desplazamientos horizontales en lugar de verticales ${ }^{23}$. Es decir, que los individuos o grupos de individuos se desplazaban socialmente no sólo en función de sus capacidades económicas sino, sobre todo, de su origen y de sus posibilidades legales. Para triunfar en Madrid era necesario reunir una serie de requisitos que permitieran al aspirante introducirse en determinados círculos de control social. Estos círculos se habian formado en un largo proceso histórico a través de un complejo sistema de relaciones económicas, políticas y sociales que ponían en contacto a Madrid con el resto del país. Como ha señalado David Ringrose la razón de ser de la capital de Es-

22 Archivo Histórico Nacional (AHN), Pruebas de Carlos III, exp. 1.722.

${ }^{23}$ Un modelo de mobilidad social semejante es el estudiado por AmELANG, James S., en La formación de una clase dirigente: Barcelona 1490-1714, Barcelona, 1986, págs. 67 y ss. 
paña se encontraba en su carácter de «ciudad política». Por esta razón Madrid se convirtió en el centro de una importante y compleja red de ralaciones económicas, que derivaban de la estructura del imperio español, de las características de la sociedad rural del interior y del tamaño y estructura económica de la propia ciudad ${ }^{24}$. Los círculos de control social serian una consecuencia lógica de este haz de relaciones económicas, de manera que la sociedad madrileña no puede ser entendida fuera de este contexto.

Se decía que el que todos los carboneros de Madrid fueran asturianos no quería decir que todos los asturianos fueran carboneros. Pero, la literatura sobre Madrid, especialmente la del siglo xIX, identificaba a los asturianos con la venta del carbón, a los gallegos con el transporte y a los montañeses con el comercio de lujo. $Y$ esto es algo que ya percibió dos siglos atrás el escritor costumbrista Francisco Santos, cuando describía a los comerciantes de lonja instalados en los alrededores de la Plaza Mayor. De manera que los hidalgos de las provincias del norte habían, desde tiempo atrás, establecido un complejo sistema de relaciones económicas y sociales para abrirse paso en el mundo del comercio o de la función pública, igual que los segovianos de Sangarcía lo hicieron para controlar parte del transporte que abastecía de trigo a la capital ${ }^{25}$.

Si Don Pedro Sainz de Baranda y Gándara no hubiera pertenecido a un conocido linaje de la Merindad de Montija, capaz de probar su hidalguía, jamás hubiera podido entrar a trabajar en la tienda de especiería y mercería que Don Francisco del Valle regentaba en Madrid. Jamás habría llegado a ser aceptado como socio en dicho negocio, como sucedió en 1758. Ni jamás hubiera terminado formando parte de uno de los prestigiosos Cinco Gremios Mayores de Madrid ${ }^{26}$. El primer Sainz de Baranda de nuestra historia se movió en un espacio social en el que las relaciones estamentales, las de parentesco y las de paisanaje estaban por encima de las relaciones de clase para progresar en la escala social.

24 Ringrose, Madrid y la economía española, págs. 13 y 14; también del mismo autor, Imperio y península. Ensayos sobre historia económica de España (siglos XVI-XVII), Madrid, 1987, págs. 125-137 y, especialmente, 138-175.

25 Ver Caro Baroja, Julio, La hora Navarra del siglo xvII. Personas, familias, negocios e ideas, cap. II, Pamplona, 1985. También García SANZ, Ángel, Desarrollo y crisis del Antiguo Régimen en Castilla la Vieja: economia y sociedad en tierras de Segovia de 1500 a 1814, Madrid, 1977, págs. 183-186: Ringrose, David R., «Ciudad, País y revolución burguesa: Madrid del siglo XVIII al siglo Xix", en Madrid en la sociedad del siglo XIX, vol. I, Madrid, 1986 , págs. 302-323.

${ }^{26}$ AHN, Diversos. Serie general, legs. 218 y 221. 
Cuando formó compañía con Valle tenía exactamente 23 años. Había abandonado su aldea, como era la costumbre, cuando sólo contaba la edad de doce años. Su contacto en Madrid debió de ser su tío Don Manuel Antonio de la Gándara, que tenía tienda abierta en la calle Imperial de Madrid y en Cádiz. Sin embargo, Don Manuel prefirió que su sobrino aprendiera los secretos del oficio en una casa ajena donde no hubiera peligro de sentirse excesivamente protegido. Era el de Valle un pequeño comercio localizado en la Plaza Mayor que se había fundado hacia $1741^{27}$. Su dueño Don Manuel del Valle era de Santa María del Llano (Valle de Mena), pueblo muy próximo a Quintanaedo. A la muerte de Valle fue Sainz de Baranda quien se hizo cargo del negocio. Aunque cuando moría el marido las viudas figuraban como las titulares del establecimiento, éstas nunca intervenían para nada en su gestión. La organización patriarcal del sistema familiar relegaba a la mujer a un muy segundo plano, de manera que siempre era un hombre quien sustituía al cabeza de familia ${ }^{28}$. Como además la familia extensa era dominante en la élite de negocios de Madrid, no es de extrañar que fueran los empleados de mayor confianza quienes suplantaran al cabeza de familia en tanto no se encontrara un sustituto. En muchas ocasiones la situación se resolvía con una boda entre el mancebo y la viuda, pero lo más frecuente es que ésta encontrara acomodo con otro comerciante 0 un semejante en rango social. Cuando la viuda de Valle decidió casarse de nuevo con otro próspero especiero, fue cuando Sainz de Baranda cambió su estatus ${ }^{29}$.

En 1762 pasó a trabajar como mancebo mayor al prestigioso comercio de Don Francisco Antonio Pérez, quien era entonces uno de los Diputados Mayores de los Cinco Gremios, y sería posteriormente nombrado Caballero de Carlos III y mayordomo de Su Majestad. Tan sólo dos años después se casaba con Petronila Gorriti que, además de ser prima suya, pertenecía a una familia en la que había comerciantes de paños y personas vinculadas a la administración y al ejército. Eran los Gorriti originarios de los valles de Mena y Arcentales, lugares muy próximos a la

${ }^{27}$ Archivo Histórico de Protocolos de Madrid (AHPM), protocolo (prot.) 19.962, folio (fol.) 12.

${ }^{28}$ Un ejemplo comparativo sobre el papel de la mujer en las sociedades mercantiles se encuentra en Socolow, Susan M., The Merchants of Buenos Aires, 1778-1810. Family and Commerce, cap. II, Cambridge, 1978. De la misma autora, «Marriage, Birth, and Inheritance: The Merchants of Eighteenth Century Buenos Aires», HAHR, 60 (1980), 387-406. Ver también el trabajo de DAVIDOFF, Leonor y HALL, Catherine, Family Fortunes. Men a women of the English Middle Class, 1780-1850, cap. IX, Londres, 1987.

${ }^{29}$ AHPM, prot. 19.962, fol. 12. 
Merindad de Montija. De esta manera Sainz de Baranda, cuyo capital al momento de casarse era de 45.000 reales, se beneficiaba de la herencia de su mujer que superaba los 350.000 reales para poder instalarse por su cuenta ${ }^{30}$. Las relaciones de parentesco y paisanaje que caracterizaban el espacio social de la élite madrileña, se manifestaban también en una marcada tendencia endogámica a la hora de elegir pareja.

Hacia 1770 el matrimonio vivía ya en la casa familiar de la calle Imperial donde Don Pedro había instalado su propia tienda de droguería y especiería. Por entonces ya había sido admitido en el gremio de especieros, uno de los prestigiosos Cinco Mayores de Madrid. En este momento Sainz de Baranda estaba repitiendo el mismo papel social que aquellos que le habían acogido en Madrid veinte años atrás. Por su establecimiento pasó un numeroso grupo de familiares y paisanos a los cuales formó e incluso a algunos de ellos les ofreció participación en sus negocios. Estaba así cumpliendo con el más elemental de los principios que definían el «habitus» de la clase comercial madrileña de finales del siglo XVIII: ayudar a su gente.

De dicho principio derivaba un modelo de familia basado fundamentalmente en las relaciones de parentesco y vecindad, todo ello combinado con un todavía vigoroso espíritu estamental. Cinco personas componían el núcleo de la familia Sainz de Baranda hacia 1780 cuando ésta se encontraba ya consciidada. Por entonces Vicente, el hijo mayor, acababa de cumplir su quince cumpleaños y Pedro, el hijo menor, sólo tenía cinco. Entre medias de los dos, Joaquín, a sus diez años, daba claras muestras de su incapacidad mental. Sin embargo, por esas mismas fechas la familia hacía extensa con la presencia de Juan Antonio de Trápaga, natural de la localidad santanderina de Ojebar, muy próxima a Quintanaedo, que ejercía el cargo de mancebo mayor en la tienda. Además, compartían la intimidad familiar Manuel de la Gándara, Julián Sainz de Baranda y Felipe Sainz de Baranda, todos sobrinos de Don Pedro y beneficiarios de su patronazgo ${ }^{31}$.

En muy poco se parecían los Sainz de Baranda al modelo de familia nuclear que tanto influyó en la creación de un nuevo marco de relaciones sociales en la Europa contemporánea. Siguiendo a $L$. Stone, esa nueva familia que, al menos en Inglaterra se consolidó ya en la segunda mitad

30 AHN, Diversos. Serie general, leg. 218; Sobre la familia Pérez ver: AHN, pruebas de Carlos III, 1796, exp. 975 y AHPM, prot. 21.086, fol. 122.

${ }^{31}$ AHPM, protocolos: 19.970 , fol. $54 ; 19.971$, fol. $49 ; 19.976$, fol. $110 ; 19.979$, fol. 12 y 19.090 , fol. 479. 
del siglo XVIII, se caracterizaba por servir menos para funciones prácticas y aportar una mayor carga de compromisos emocionales y sexuales; por ser más conyugal y menos orientada hacia la relación de parentesco; más unida por lazos afectivos y menos responsable de los desasistidos, quienes ahora encontraban en las autoridades públicas su patronazgo (...); más preocupada por los menores y menos orientada hacia los adultos y, finalmente más privada y menos pública. Ignoro si los Sainz de Baranda practicaron entre sí un tipo de relación fundada en el individualismo afectivo, pero el comportamiento demográfico descrito anteriormente no es el de una familia cuyo desarrollo, tanto biológico como social, transcurriera con independencia respecto de la comunidad a la que pertenecía. Por el contrario, el modelo de familia característico de la élite comercial de Madrid en la transición del siglo XVIII al XIX, se aproximaba más a aquel de la temprana Edad Moderna que al que caracterizó a la sociedad europea posterior a 1750. Se trataba de una familia extensa constituida por la pareja, los hijos y un grupo de protegidos y servidores cuyo funcionamiento radicaba en la aceptación del principio de autoridad patriarcal ${ }^{32}$.

Dicho patriarcalismo se puso de manifiesto en dos ocasiones trascendentales para la continuidad de la familia. La primera se refiere a la elección de la pareja más idónea para los hijos, y la segunda a la forma en que Don Pedro estableció todo un sistema de patronato, con el fin de perpetuar su nombre y el de los suyos después de su muerte. Ambas ocasiones demuestran que la autoridad paterna y el interés del grupo se anteponían a los intereses particulares de cada uno de sus componentes.

Sería ingenuo pensar en un romántico idilio que condujera al nada casual matrimonio de los hermanos Sainz de Baranda (Vicente y Pedro), con sus primas las hermanas Manuela y Josefa San Juan y Santa Cruz. Ambas procedían del Valle de Arcentales y eran sobrinas políticas del patriarca del grupo familiar ${ }^{33}$. Es claro que dichos matrimonios respondían al interés por mantener la continuidad de la familia y por respetar una norma que garantizaba también la continuidad de todo un grupo

32 StONe, L., The Family, Sex and Marriage in England, 1500-180, cap. XIII, Londres, 1977. Sobre las diferencias entre familia extensa y familia nuclear y su papel en la historia ver además, FLANDRIN, Jean Louis, Origenes de la familia moderna, cap. II, Barcelona, 1979; Goody, Jack, The Development of the Family and Marriage in Europe, Cambridge, 1983, pág. 183 y ss.; WaLL, Richard (edit.) Family Forms in Historic Europe, Cambridge, 1983, págs. 282 y ss.; SHORTER, Edward, The Making of the Modern Family, Nueva York, 1975.

33 AHPM, prot. 19.982, fol. 473. 
social. Vicente y Pedro habían nacido en Madrid y su vida social estaba ligada a la capital. Sus respectivas esposas fueron desplazadas ex-profeso desde el Valle de Arcentales para consumar sus matrimonios. Todo hace pensar en una decisión interesada tomada de antemano. Sin embargo, no cuesta trabajo entender la sumisión de los hijos ante semejante decisión. Ellos habían sido educados para ese tipo de matrimonio y su vida social había transcurrido en los límites de un círculo social muy restringido ${ }^{34}$. Una buena muestra de esa restringidísima sociabilidad se encuentra en la lista de los invitados que asistieron a la boda de Pedro en 1796. En ese momento la familia ocupaba ya un lugar de prestigio entre la élite de negocios de Madrid. Allí estuvieron presentes los García de la Prada, los Iruegas, los Caballero, los Pérez y los Ruiz de Santayana entre otros, o sea, los más selectos miembros de los Cinco Gremios Mayores. Pero fuera de los pertenecientes a este círculo no aparece ningún apellido destacable. Es una muestra más de que los límites de sociabilidad no traspasaban la familia, el gremio o aquellas organizaciones como las hermandades, cofradías o congregaciones, en las que se combinaban la práctica religiosa con la identidad gremial, el origen social y la relación de pertenencia a un mismo lugar geográfico ${ }^{35}$.

El patronazgo no sólo se ejercía en el ámbito de la relación laboral o de la familia sino que tenía una proyección como práctica social. La costumbre de auxiliar a quienes por lazos de sangre, amistad, servicio o paisanaje se hallaban ligados al grupo familiar, era una fórmula tradicional entre los comerciantes ricos. Dicha fórmula tenía su fundamento en el patriarcalismo familiar por un lado y por el otro en una sincera religiosidad muy destacada hacia la práctica caritativa. La caridad y el patronazgo suplían así en la sociedad del Antiguo Régimen ciertas competencias que serian asumidas posteriormente por el Estado ${ }^{36}$.

${ }^{34}$ Para un análisis de los conflictos entre efectividad individual y autoridad patriarcal ver el interesante trabajo de SEED, Patricia, To Love, Honor and Obey in Colonial México. Conflicts in Marriage Choice, 1574-1821, Stanford, 1987, págs. 227 y ss.

35 AHN, Diversos. Serie general, legs. 218 y 219.

${ }^{36}$ Sobre las relaciones sociales de patronazgo ver EISENSTADT, S. N. AND Roniger, I., Patrono, Clients and Friends, Interpersonal Relations and the Structure of Trust in Society, Cambridge, 1984, págs. 48 y ss. Un ejemplo de la importancia de las relaciones familiares en la consolidación de una élite económica es el presentado por MCDONOGH, Gary W., en Good Families of Barcelona. A Social History of Power in the Industrial Era, ver caps. Ill y IV, Princeton, 1986. Sin embargo, han sido los latinoamericanistas quienes más han resaltado la importancia de las relaciones familiares en la formación y desarrollo de las sociedades, tanto de la época colonial como de la época nacional. Los ejemplos pueden tener un valor comparativo. Ver CRUz, Jesús, "Las élites iberoamericanas a finales del siglo XVIII. Sobre modelos y procesos comparados", en Cuadernos de Historia Moderna (en prensa). 
La élite comercial madrileña de la transición del siglo XVIII al XIX fue extremadamente devota de estas prácticas caritativas y de patronazgo. Ahora me limitaré al caso específico de los Sainz de Baranda, pero los ejemplos se podrían extender a otras muchas familias ${ }^{37}$. Don Pedro ni siquiera esperó a su muerte, como era lo habitual, para empezar una importante cadena de fundaciones caritativas que supusieron un buen mordisco a su fortuna. Ya en 1797 fundó en Madrid una capellanía para su sobrino carnal Don Narciso Sainz de Baranda ${ }^{38}$. Pero fue en su testamento, otorgado en 1804, donde se puede apreciar ese inagotable espíritu patrocinador. Ordenó se dedicasen 50.000 reales a la fundación de una capellanía en su villa natal, y otros 50.000 para la apertura de una escuela de primeras letras. Sin embargo, lo más llamativo de dicho documento es la espectacular asignación de fondos dedicados a obras de caridad que superaba con creces lo que se podría considerar como habitual. No cabe duda de que nuestro personaje era un hombre profundamente devoto ${ }^{39}$.

La muerte sorprendió a Don Pedro Sainz de Baranda y Gándara en un momento menos propicio para los negocios. Corría el mes de diciembre de 1809 en un Madrid que sufria las desastrosas consecuencias de la invasión francesa. Esta circunstancia afectó a la casa de comercio y giro de Sainz de Baranda como a otras muchas de sus mismas características. Tan sólo diez años antes dicha casa había dado el salto de simple comercio minorista a ser además casa de giro. Así los Sainz de Baranda se convertían en comerciantes banqueros y pasaban a formar parte del grupo más selecto de la élite de negocios de Madrid (Apéndice 1). El inventario de sus bienes se realizó seis años después de la muerte de Don Pedro debido a la situación de inestabilidad que se vivió en Madrid después de 1808. Por entonces la familia Sainz de Baranda era ya conocida en la capital a pesar de que su economía por aquellos años no fuera tan boyante. Era el momento de iniciar una nueva etapa cuya principal característica sería el asalto a la vida pública ${ }^{40}$.

${ }^{37}$ CRUZ, Jesús, «Cambistas madrilerios en la segunda mitad del siglo XVIII», en BAHAmonde Magro, Angel y Otero Carvajal, Luis E., (Coord.), Madrid en la sociedad del siglo $X I X$. vol. I, Madrid, 1986, págs. 454-474.

${ }^{38}$ AHPM, prot. 19.983 , fol. 637.

39 AHPM, prot. 19.990 , fol. 479.

$40 \mathrm{AHN}$, Diversos. Serie general, leg. 218. 
Relata Modesto la Fuente en su Historia de España una de las primeras acciones emprendidas por los revolucionarios de 1820 en Madrid de la siguiente manera: «Llegado hubieron a la Casa de la Villa se procedió a pasar oficios a los que fueron concejales en 1814, siendo desde luego aclamado alcalde primero Don Pedro Sainz de Baranda, que tan señalados servicios había hecho a la capital durante la dominación francesa, y alcalde segundo Don Rodrigo de Aranda (...). Los sujetos que se decian comisionados del pueblo propusieron inmediatamente de palabra y por escrito que aquel mismo día el reinstalado ayuntamiento recibiese del rey el juramento de la constitución. Acórdose así y en su virtud anticipóse el Marqués de Miraflores a dar la noticia a S.M. de este acuerdo y del resultado de su comisión. Siguiéndole el ayuntamiento y los comisionados del pueblo, y recibidos todos por el rey en el salón de embajadores, juró Fernando a su presencia bajo el dosel del trono, la constitución política de la monarquía promulgada en Cádiz el 19 de marzo de $1812 "{ }^{41}$.

De esta forma culminaba la carrera pública de uno de los hijos de aquel hidalgo provinciano que había emigrado a Madrid para hacer fortuna como comerciante. Y lo hacía comprometiéndose con la defensa de los principios de libertad de acción e igualdad ante la ley, que constituian el fundamento de la doctrina doceañista. Por ello, si se considerara a Pedro Sainz de Baranda y Gorriti desde el punto de vista de su comportamiento político, no habría duda en catalogarle como burgués ejemplar. Dicho de otra manera, sería Sainz de Baranda un claro ejemplo de esa nueva clase social que progresivamente se fue haciendo con el poder para transformar las estructuras jurídicas y sociales en el sentido del capitalismo. Vistas así las cosas, familias como la de los Sainz de Baranda constituirían el mejor testimonio para sostener que, en efecto, hubo en España una revolución burguesa. Pero esto sería atacar el problema de una manera bastante parcial, que es como desgraciadamente se ha hecho hasta el momento.

Para poner las cosas en sus justos términos sería fundamental preguntarse hasta que punto el alcalde Sainz de Baranda era, en efecto, representativo de una nueva clase social. Mejor dicho, hasta que punto

${ }^{41}$ Lafuente, Modesto, Historia de España, vol. 10, Madrid, 1889, págs. 300. 
era nueva la clase o grupo social a la cual pertenecía. Pero la evaluación del grado de novedad no puede fundamentarse una vez más en la observación exclusiva de sus posicionamientos objetivos. Estaríamos equivocándonos de nuevo si sólo atendiéramos al análisis de su práctica política o de su comportamiento económico. En este punto es necesario entender literalmente la idea thompsomiana de «formación» (making) de una clase social, no sólo por lo que dicha clase social pueda representar objetivamente, sino también de la forma en que se representa a sí misma. Por ejemplo con palabras: "burguesía", "clase obrera», "honor"; a través de sus símbolos: banderas, escudos, uniformes; o a través de sus organizaciones: sindicatos, cofradías, corporaciones, etc. Lo realmente importante es saber hasta que punto el alcalde Sainz de Baranda fue consciente de que, en efecto, representaba algo innovador. Deberíamos ir incluso más lejos preguntándonos si nuestro hombre, que había abrazado un credo político revolucionario, fue consecuente en su práctica social cotidiana introduciendo cambios que hicieran de la sociedad española una sociedad más burguesa; o sea, una sociedad en la que, al menos, los principios de libertad de acción e igualdad ante la ley fueran algo más que una mera declaración de intenciones.

Hacer de la sociedad española una sociedad más burguesa implicaba en cierto sentido conseguir una sociedad más moderna. Reconozco que el concepto es demasiado ambiguo por su multivalencia, pero se me ocurre que entre 1812 y 1855 en España modernizar en el sentido social quería decir, al menos, tres cosas fundamentales: primero romper con la práctica exclusivista de la tradición estamental; segundo y consecuencia de lo anterior, favorecer un espacio social en el que los individuos dispusieran de las mismas oportunidades; y finalmente, posibilitar una sociedad más laica y menos dependiente de la práctica religiosa. Para todo ello se precisaba algo más que reformas de orden político-institucional. Había que conseguir cambiar, al menos parcialmente, el sistema dominante de normas, significados, valores y símbolos, es decir, cambiar la cultura social. Sólo en la medida en que dicho cambio se hiciera efectivo, primero entre las élites burguesas y luego en el conjunto social, tendría sentido hablar de una revolución burguesa.

Entre 1839 y 1840 Sainz de Baranda, que por aquel entonces era ya regidor perpetuo, fue nombrado vocal de la comisión de instrucción pública primaria de la provincia de Madrid. Fue el último cargo público que tuvo en la capital antes de su muerte, pero no era el primero que tuviera relacionado con la educación. Dejemos para otra ocasión el análisis de sus ideas sobre este asunto por muy interesantes que estas sean y fijémonos en un hecho que viene más al caso: su renuncia cuando 
apenas acababa de cumplir un año en el cargo. Sucedió que, entre otras atribuciones, dicha comisión estaba encargada de supervisar las oposiciones a maestros de primeras letras en la provincia y él fue uno de los encargados de realizar las pruebas. Como casi todo lo relacionado con la Administración en aquellos tiempos dichas pruebas de selección no fueron nada limpias y las plazas se otorgaron a familiares, a amigos y a paisanos de los seleccionadores. No se sabe a ciencia cierta si es que en el reparto los favoritos de Sainz de Baranda salieron mal parados o si su postura de denuncia fue sincera, pero lo cierto es que a raíz de aquello decidió retirarse a su casa de campo en Villaviciosa de Odón. Además acababa de pasar su 65 cumpleaños ${ }^{42}$.

Lo que resulta chocante es que nuestro hombre hiciera gala de un exceso de celo en su actividad pública cuando en muchas de sus decisiones privadas se sirvió de los mismos criterios de favoritismo y protección para preservar la continuidad de su familia. Veámos algunos ejemplos y nos convenceremos de que hubo un cierto abismo entre el hombre público y el hombre que tenía que tomar decisiones que afectaban a su futuro y el de los suyos.

En 1820 inició un pleito familiar para conseguir una capellanía en la cual colocar a su hijo primogénito. No parece que el bueno de Sainz de Baranda hubiera asimnilado de momento aquello de la equiparación de las oportunidades, que debía de ser una característica de la nueva sociedad liberal burguesa ${ }^{43}$. Como se ha visto anteriormente las capellanías eran una de las instituciones más utilizadas en la sociedad del Antiguo Régimen para ejercer patronazgo y perpetuar la familia. El caso es que nuestro hombre había decidido conceder estudios a su primogénito y éste había respondido con una muy marcada vocación por el sacerdocio. No hay que ser mal pensados y suponer que esta fue una decisión que el joven Pedro Sainz de Baranda y Santa Cruz tomó por sí mismo. La capellanía había sido fundada por Domingo Gorriti en 1782 y se localizaba en el valle de Arcentales. El litigio duró varios años y no se resolvió hasta 1828, año en que se reconocieron los derechos que por parentesco directo correspondieron a los Sainz de Baranda en vez de a los San Juan y Santa Cruz. En este punto el comportamiento social de los Sainz de Baranda resultaba una continuación del mostrado por la generación anterior, es decir, estaba más próximo de la sociedad estamental que de

${ }^{42}$ AHN, Diversos. Serie general, leg. 221.

${ }^{43}$ AHN, Diversos. Serie general, legs. 217 y 224. 
la sociedad burguesa. Este continuismo es igualmente perceptible en otros aspectos de la vida social de nuestro protagonista.

Por ejemplo, cuando en 1816 fue nombrado diputado de la sala de gobierno para representar al estado de caballeros hijosdalgo de la heroica villa de Madrid, cargo que ejerció hasta su exilio en $1823^{44}$. O cuando un año más tarde se sometía a todas las pruebas de nobleza exigidas para conseguir un hábito de la prestigiosa orden de Caballeros de Carlos III. Teniendo además en cuenta que dicho favor se le otorgaba no por haber sido director del Banco de San Carlos o por su labor como alcalde de Madrid, sino por servir durante tres años la comisión caritativa de director del colegio de niños desamparados ${ }^{45}$.

Tampoco en lo que se refiere a las formas de sociabilidad se pueden percibir cambios notables respecto de la generación anterior. Fuera de las horas empleadas en sus diversas actividades como director del Banco de San Carlos, edil del ayuntamiento o en su propia casa de comercio, parece que lo que más atrajo a nuestro hombre fueron las asociaciones de carácter religioso y caritativo. Desconocemos a lo largo de su vida ninguna vinculación con tertulias políticas o culturales. Sí sabemos que durante muchos años fue hermano mayor de la cofradía del Santísimo Sacramento en la parroquia de Santa Cruz. La misma cofradía a la que habia pertenecido su padre y otros familiares suyos junto a un numeroso grupo de comerciantes del mismo gremio. Sabemos también que todavía en 1820 era miembro activo de la congregación de Nuestra Señora de Bien Aparecida, que desarrollaba sus actividades en el convento de San Felipe el Real. Dicha congregación admitía sólo a los hijos y originarios de las montañas de Burgos y Cantabria ${ }^{46}$. No cabe duda de que Sainz de Baranda fue un hombre tan devoto como lo fuera su padre y como lo serían sus hijos. Lo demuestra el hecho de que su sobrino carnal, educado bajo su tutela por la temprana muerte de su hermano Vicente, decidiera también abrazar el sacerdocio.

Pero donde mejor se observa ese continuismo es en la propia percepción que Sainz de Baranda tenía de lo que debía de ser un comportamiento socialmente ejemplar. Podemos analizar estas ideas en un documento escrito en 1814 con el fin de defenderse de una acusación de afrancesamiento que le lanzó Espoz y Mina. Resulta curioso observar como ciertos cambios en el vocabulario utilizado no comportaban, sin

44 AHN, Diversos. Serie general, leg. 218.

45 AHN, Pruebas de Carlos III, exp. 1.722.

${ }^{46}$ AHN, Diversos. Serie general, leg. 219. 
embargo, contenidos diferentes. La primera referencia, por ejemplo, se dirigía a resaltar el "patriotismo" de su padre. Pero el significado de dicho concepto no se identificaba exactamente con la idea de pertenecer a una comunidad nacional, sino más bien con un lugar de nacimiento. Quiere esto decir que en vez de colocar como ejemplares valores la lengua, la historia, la cultura o el compromiso con un gobierno concreto, Sainz de Baranda colocaba el estamento, la religión, la familia y el paisanaje. La primera cualidad que definía el patriotismo de su padre era el haber sido hijo de labradores nobles y honrados aunque pobres, y el haber trabajado con tesón para ganar una fortuna regular. La segunda, el haber sido tan religioso que hizo casi de nuevo y surtió de cuanto puede imaginarse a la parroquia de su lugar. La tercera, el haber sido tan interesado en el bien de sus parientes que puso en carrera y dotó para tomar estado al menos a dieciocho de ellos. La cuarta, el haber sido tan verdaderamente «liberal» que sirvió de apoyo a más de treinta jóvenes para tomar en su compañía los rudimentos del comercio y poder colocarse después en la Corte o en las Indias. La quinta y última, el haber sido tan amante de su país, las Merindades de Castilla, que construyó un pósito y una escuela de primeras letras para auxilio de sus vecinos. Estos sanos principios de religión y de virtudes cívicas, escribía Sainz de Baranda, han sido los fundamentos del verdadero patriotismo, que si mi amor propio no me engaña he heredado en grado no común. No cabe duda que los principios básicos que caracterizaron la cultura social de la primera generación no habían sufrido importantes alteraciones ${ }^{47}$.

Los peores momentos de la familia coincidieron con el prolongado exilio del, por entonces, ex-alcalde entre 1823 y 1830 . Durante aquellos años nuestro hombre se dedicó exclusivamente a los negocios un tanto desengañado de la vida política ${ }^{48}$. Inició contactos con comerciantes de la Habana, cómo no todos ellos familiares y paisanos suyos, para transportar tabaco desde aquella isla a París. No se enriqueció en esta empresa y a su regreso a Madrid volvió a sus actividades públicas siempre en el ámbito del gobierno municipal o provincial. Entonces combinó sus tareas de hombre público con las de propietario agrario de tipo medio. Como muchas familias de su época, los Sainz de Baranda, supieron transformar una fortuna basada en el crédito comercial y las inversiones en deuda pública, por otra basada en la propiedad de bienes raíces (Apéndice II). Una parte de dichas raíces procedían de su herencia y de

\footnotetext{
47. AHN, Diversos. Serie general, leg. 226.

${ }^{48}$ AHN, Diversos. Serie general, legs. 217, 220, 224 y 226.
} 
la de su mujer. Sus propiedades en Aragón correspondían a un coto redondo en la localidad de Buñuel que el Conde de Altamira enajenó para ser vendido en 1808. Se trataba de tierras de regadío próximas al canal de Tauste, en cuya construción tuvo bastante que ver el propio Sainz de Baranda ${ }^{49}$. Murió Don Pedro en Villaviciosa de Odón en 1855 dejando tres hijos varones. El mayor, Perico como cariñosamente le llamaba su padre, fue párroco de Santa Cruz después de doctorarse en derecho civil y canónico. Miembro de la Real Academia de la Historia fue un hombre de gran erudición, como lo demuestra el hecho de que continuara la obra iniciada por Flórez y fuera autor de la inmensa Colección de Documentos Ineditos para la Historia de España. Del pequeño, Manuel, no ha quedado ninguna noticia. De Isidoro, el mediano, sabemos que en 1866 era Inspector General de Minas.

III

Como todos los personajes galdosianos, Don Manuel María del Pez, era la réplica ficticia de un tipo social muy característico de la sociedad madrileña posterior a 1850. Alto funcionario de la Administración isabelina, definía su personalidad más por una cínica cautela respecto de la cosa pública que por un firme compromiso con el poder para el que prestaba sus servicios. Aunque sus simpatías politicas se decantaban más del lado de los moderados, su auténtica obsesión era la de agradar a todos, de ahí que, incluso entre los revolucionarios, tuviera muchos devotos. Para Pez la administración era una tapadera de fórmulas baldías, creadas para encubrir el sistema práctico del favor personal, cuya clave está en el cohecho y las recomendaciones. Cuando llegó la revolución de septiembre de 1868 nuestro alto funcionario entrevió la posibilidad de convertirse en un cesante. Pero, iqué feliz casualidad!, casi todos los individuos que compusieron la junta revolucionaria eran amigos suyos. Algunos tenían con él parentesco, es decir, que eran algo Peces. En el gobierno provisional tampoco faltaban amistades y parentescos y donde quiera que volviera nuestro amigo sus ojos, veía caras pisciformes. Llamémosle a ésto filosofía de la historia más que casualidad ${ }^{50}$.

49 AHN, Diversos. Serie general, legs. 218 y 225.

50 Pérez Galdós, Benito, La de Bringas, Obras completas, vol. IV, Madrid, 1957, págs. 1581 y 1656. 
Porque la abundancia de "pisciformes" en la sociedad española de finales del siglo XIX no era algo casual. Era el resultado de la pervivencia de parte de aquel conjunto de normas, significados, valores y símbolos, que constituyeron la cultura de las élites del Antiguo Régimen. Dicha persistencia es perceptible en el entramado político-social-geográfico que constituyó el sistema de la Restauración. Pero el peso de la amistad, la familia o las solidaridades regionales es algo que se mantiene incluso en la práctica social hasta nuestros días ${ }^{51}$.

Para entender estas pervivencias creo que la historia de los Sainz de Baranda puede tener valor paradigmático. Desde sus orígenes de hidalgos provincianos hasta su salto a la vida pública esta historia ofrece algunas claves para descifrar el problema.

En primer lugar, como ya se ha señalado en otras ocasiones, por su origen social los Sainz de Baranda no eran burgueses sino hidalgos. Fueron estos hidalgos de provincias los que formaron el grueso de la élite "burguesa" madrileña (administración, negocios y profesiones) durante la crisis del Antiguo Régimen ${ }^{52}$. Por su condición de hidalgos no constituían una nueva clase social, sino que eran una fracción del tradicional estamento nobiliario. Como se puede deducir de los trabajos de Caro, Bravo Lozano, Bahamonde y Otero, dichos hidalgos coparon determinados círculos de control económico, social y político existente en Madrid desde la segunda mitad del siglo XVII (y probablemente antes) hasta finales del siglo $X \mathrm{X}^{53}$. Fueron, desde luego, grupos familiares diferentes, pero su origen social y su cursus honorum para situarse en la corte apenas si sufrió variaciones.

En segundo lugar parece que la cultura social de esta élite no cambió en aspectos que resultaban claves para propiciar un proceso de mo-

51 Varela Ortega, José, Los amigos políficos. Partidos, elecciones y caciquismo en la Restauración (1875-1900), Madrid, 1977, págs. 353-365. Sobre los orígenes del caciquismo, ver HERR, Richard, "Spain" en D. Spring (edit.): European Landed Elites in the Nineteenth Century, Baltimore, 1977, 98-126.

52 Ver a este respecto HerR, Richard, Rural Change and Royal Finances in Spain at the End of the Old Regime, sobre todo el capítulo XIX. Berkeley, 1989. También MoraLES Moya, Antonio, Reflexiones sobre el estado español del siglo xVII, Madrid, 1987, pág. 33.

${ }_{53}$ Caro Baroja, Julio, La hora Navarra del siglo xvil..., ver especialmente el cap. I; Bravo Lozano, Jesús, "Don Fancisco de Horcasitas. Las posibilidades de Madrid a finales del siglo XVIl," Estudios de historial social, 36-37, (1986, enero-junio), 497-521; BAHAMONDE Magro, Angel y Otero CarVAJAL, Luis E., “La reproducción patrimonial de la élite burguesa madrileña en la Restauración. El caso de Francisco de las Rivas y Ubieta, Marqués de Mudela, 1834-1882," en Bahamonde, A. Y Otero CARVAJal, L. E., (edits.), La sociedad madrileña durante la Restauración, 1876-1931, Madrid, 1989, págs. 524-294. 
dernización de la sociedad. El hecho de que fueran hidalgos no resulta suficiente para explicar las razones de la pervivencia de ciertas prácticas sociales. Digamos que a lo sumo ayudaría a encontrar una explicación, pero no existe ninguna regla histórica que impida pensar en que una fracción de la aristocracia pudiera modernizar la sociedad. Lo que ocurrió en la sociedad madrileña y diría que incluso en la mayor parte de la sociedad española, es que la cultura social hegemónica hasta finales del siglo XIX era fundamentalmente aristocrática. Como se ha visto en el caso de los Sainz de Baranda, no es que su cultura fuera la misma que la de la vieja aristocracia castellana, pero en esencia sí se puede decir que estaba, en lo fundamental, impregnada de valores aristocráticos.

Para explicar la pervivencia de dichos valores en el espacio social de la capital habría que recurrir a dos procesos históricos diferentes pero relacionados entre sí. En primer lugar como ya se ha señalado, al papel de «ciudad política» que desempeñó Madrid en su relación con el resto del país. En este sentido la consolidación de esa "élite hidalga» sería una consecuencia de dicho proceso, probablemente la más importante desde el punto de vista social. En segundo lugar a la diacronía natural a todo proceso histórico entre cambios culturales y cambios políticos o económicos. Parece que el espacio social de la élite de negocios madrileña se definió más por la persistencia de cierto "habitus" que por una sincera voluntad de cambio. Dicho "habitus» se caracterizó, básicamente, por la existencia de un principio de exclusividad que tendía a diferenciar a los componentes del grupo del resto de la sociedad. Ese principio, que con el paso del tiempo se fue transformando en un sentimiento más que en una norma, tenía su fundamento en el linaje, el parentesco y el paisanaje. Su génesis social habría que buscarla en una práctica comúnmente aceptada cuyos fundamentos eran la solidaridad y el patronazgo. El transfondo religioso de dicha práctica me parece indiscutible. Así en la sociedad del Antiguo Régimen las relaciones de exclusividad fueron norma comúnmente aceptada pero en la sociedad liberal tal marco de relaciones degeneraría en el amiguismo y en el cohecho (Oligarquía y Caciquismo).

A mediados del siglo XIX el escritor inglés Samuel Smiles desarrollaba la doctrina del self-help en una serie de biografías publicadas por aquellos años. Con tesón, voluntad de ahorro, costumbres ordenadas y un poco de ambición cualquier individuo, no importaba su rango social, podía llegar a ser rico y socialmente prestigiado. Smiles representaba el triunfo ideológico de las clases medias. Pero lo más importante es que todos los personajes biografiados eran reales y sus historias habian su- 
cedido alguna vez. No hay en España una literatura semejante ${ }^{54}$. Una revista como el Museo de las Familias incluía ya en 1840 relatos de personajes que se habían hecho a sí mismos, pero eran siempre ficticios. En la novela del último tercio del siglo XIX dicho tipo aparecía casi siempre personificado en la figura del indiano ${ }^{55}$. $Y$ es que desde el punto de vista de la cultura social, la sociedad española de mediados del siglo XIX, comparada con la inglesa o la francesa, parecía muy poco burguesa. Con estos presupuestos seguir manteniendo el paradigma de la revolución burguesa para explicar los cambios históricos producidos en España entre 1812 y 1837 , me parece un ejercicio de dogmatismo que en nada facilita el entendimiento histórico. Creo que es el momento de iniciar una profunda revisión de dicho paradigma, semejante a la que los historiadores de la economía han realizado sobre los ritmos de crecimiento a lo largo del siglo XIX. Es decir, cambiando los presupuestos metodológicos, siendo más flexibles en la aplicación de modelos teóricos y, sobre todo, intentando conocer mejor eso a lo que hemos venido llamando burguesía.

${ }^{54}$ Sobre la doctrina de Smiles, ver FiELDEN, Kenneth, «Samuel Smiles and Selph Heplh", en Victorian Studies, 1968, december, págs. 155-176.

${ }^{55}$ «El arte de hacer fortuna», en Museo de las familias, Madrid, 1846, págs. 5-8. 
APÉNDICE I

Evolución de la fortuna de Sainz de Baranda y Gándara (en reales de vellón)

Capital en 1762 45.000

Herencia de su esposa en 1762 357.000

Avanzo de sus negocios realizado en 1790

1.051 .928

Inventario de bienes realizado en 1815 :

Bienes muebles

Pinturas

Alhajas 23.160

Mobiliario y ropas 28.200

Bienes raíces

Casa en la calle Silva núm. 10 45.000 Inversiones

Créditos contra el estado 231.870

Acciones del Banco de S. Carlos 128.000

Acciones de la Cia. de Filipinas

Acciones de los Cinco Gremios 111.778

TOTAL

596.508

\section{APÉNDICE II}

Evolución de la fortuna del alcalde Sainz de Baranda (en reales de vellón)

Avanzo de los haberes a finales de 1845

Bienes muebles

Pinturas 12.000

Alhajas 45.000

Mobiliario y ropas 55.000

Libros 30.000

Bienes raíces

Hacienda en Buñuel

370.000

Casa de la calle Silva

Casa y tierras en Villaviciosa de Odón 225.745 Inversiones

En diversos créditos contra el Estado 